\title{
A Comparison of Six Legged ODE (Open Dynamics Engine) Based Gait control Algorithm and Standard Walking Gaits
}

\author{
Şahin Y1ldırım ${ }^{1}$, Erdem Arslan ${ }^{2 *}$ \\ ${ }^{1}$ Erciyes Üniversitesi, Mühendislik Fakültesi, Mekatronik Mühendisliği Bölümü, Kayseri, Türkiye (ORCID: 0000-0001-6870-7932) \\ ${ }^{2}$ Erciyes Üniversitesi, Mühendislik Fakültesi, Mekatronik Mühendisliği Bölümü, Kayseri, Türkiye (ORCID: 0000-0002-4961-4922)
}

(This publication has been presented orally at International Conference on Human-Computer Interaction, Optimization and Robotic Applications-HORA 2019 congress.)

(First received 1 August 2019 and in final form 24 October 2019)

(DOI: $10.31590 /$ ejosat.637865)

ATIF/REFERENCE: Yildirim, S., \& Arslan, E. (2019). A Comparison of Six Legged ODE (Open Dynamics Engine) Based Gait control Algorithm and Standard Walking Gaits. European Journal of Science and Technology, (Special Issue), $242-255$.

\begin{abstract}
In legged robots, there are changes in the sequence of legs and the foothold positions depending on the speed. The walking sequence, known as gait, is important for the robot's ability to move in a stable and less energy-consuming way. In this study, the previously developed ODE-based gait control algorithms for a six-legged mobile robot and the standard walking gaits were compared in terms of stability and repeatability. In the ODE-based gait control algorithm, dynamic effects are not neglected, as in standard gait patterns. Owing to this, the ODE-based gait controller has the ability to constantly balance itself against external disturbances. In order to test this feature of the control algorithm, the same comparison operations were repeated for a fixed motion scenario on a rotatable inclined floor. In this study firstly layered control architecture has explained which developed for ODE-based controllers. Thereafter, servo motor controllers, ODE based stability and ODE based gait controllers used in robot are introduced respectively. After in order to make the performance of these controllers comparable to the methods in the literature, standard gait patterns have been introduced. Following this section, the performance criteria to be used in the comparison procedures and the reasons for their selection are given. Later on, the rotatable inclined floor, which was builded in order to demonstrate the performance of the robot and controller used in the test system better, has explained. Afterwards, an experimental scenario in which the slopes are changed periodically over time was determined, with the aim of using this scenario in comparison experiments in which performed on the rotatable inclined floor. In the comparison results section, the experimental performance results shown by ODE-based gait controller and standard walking arrangements are given in detail through this test system and comparison criteria. As a result of the study, a 65 percent improvement was observed in stability of robot, both flat and inclined floor according to standard walking gaits.
\end{abstract}

\section{Altı Bacaklı ODE (Open Dynamics Engine) Tabanlı Yürüyüş Kontrol Algoritması ile Standard Yürüyüş Düzenlerinin Karşılaştırılması}

$\ddot{\mathbf{O} z}$

Bacaklı robotlarda, hareket hızına bağlı olarak, bacakların yere temas sıralarında ve pozisyonlarında farklılıklar görülmektedir. Gait olarak bilinen bu yürüyüş sırasının robotun kararlı ve daha az enerji harcayacak bir şekilde hareket edebilmesi açısından önemi büyüktür. Bu çalışmada daha önce altı bacaklı bir mobil robot için geliştirmiş olduğumuz ODE tabanlı yürüyüş kontrol algoritmaları ile standard yürüyüş düzenlerine sahip algoritmalar, denge ve kararlılık açısından karşılaştırılmıştır. ODE tabanlı yürüyüş kontrol

\footnotetext{
* Corresponding Author: Erciyes Üniversitesi, Mühendislik Fakültesi, Mekatronik Mühendisliği Bölümü, Kayseri, Türkiye, ORCID: 0000-00024961-4922, erdemarslan@ erciyes.edu.tr
} 
algoritmasında, standard gaitlerdeki gibi dinamik etkiler ihmal edilmemektedir. Bu sayede ODE tabanlı yürüyüş kontrolörüne, dışardan gelen bozucu etkenlere karşı kendisini sürekli olarak dengeye getirebilme özelliği katılmıştır. Kontrol algoritmasının bu özelliğini test edebilmek için aynı karşılaştırma işlemleri eğimi değiştirilebilir hareketli bir platform üzerinde sabit bir hareket senaryosu için tekrarlanmıştır. Çalışmada ilk olarak daha önce geliştirilen ODE tabanlı kontrolörler için belirlenen katmanlı kontrol mimarisi açıklanmıştır. Daha sonra sırasıyla robotta kullanılan servo motor kontrolörleri, ODE tabanlı denge ve ODE tabanlı yürüyüş kontrolörleri tanıtılmıştır. Ardından bu kontrolörlerin performansını literatürdeki metotlarla karşılaştırılabilir bir hale getirmek için standard yürüyüş düzenleri tanıtılmıştır. Bu bölümün sonrasında karşılaştırma işlemlerinde kullanılacak performans kriterleri ve bunların seçim sebepleri verilmiştir. Daha sonra da deney sisteminde kullanılan robotun ve kontrolörün performansını daha iyi bir şekilde ortaya koymak amacı ile kurulan eğimi değiştirilebilir platform açıklanmıştır. Sonrasında ise, bu eğimi değiştirilebilir platform üzerinde yapılacak karşılaştırma deneylerinde kullanılması amacı ile eğimlerin zamana bağlı olarak periyodik bir şekilde değiştirildiği bir deney senaryosu belirlenmiştir. Karşılaştıma sonuçları bölümünde ise bu deney sistemi ve karşılaştırma kriterleri üzerinden, standard yürüyüş düzenleri ile $\mathrm{ODE}$ tabanlı yürüyüs kontrolörünün göstemiş olduğu deneysel performans sonuçları detaylı bir şekilde verilmiştir. Çalı̧̧ma sonunda standard yürüyüş düzenlerine robotun stabilitesinde hem düz hem de eğimli zeminlerde yüzde 65 oranında bir iyileşme gözlenmiştir.

Anahtar Kelimeler: Bacaklı robot, Yürüyen Robot, Yürüyüş Analizi, Eğimli zemin.

\section{Introduction}

Mobile robots are systems that can perform the tasks defined in a space without being connected to any place. In robotics, the term manipulation is generally used instead off moving. In the manipulation process, a robot placed in a fixed position moves objects by applying different forces at different times [1]. In mobile robots, it is more appropriate to use the term locomotion instead of manipulation [2]. In the locomotion process, the environment in which the robot is placed is accepted as constant and the robot moves itself by applying some forces on this environment.

Talking about locomotion of mobile robots, the first system that comes to mind is the walking mechanisms used by living creatures in nature. Walking motion is performed by following the sequential contact points between the animal leg's endpoint and the ground [3]. With these contacts points which occurs between the ground and the end point of the leg, it is possible to move with legs even in difficult terrain [4]. Although legged systems provide mobility even in harsh field conditions, legged movement systems has more complex application and control problems than other alternatives.

In addition to these basic gait control techniques, researchers working on gait control in leg mobile robots have often sought to identify optimal gait patterns to improve energy efficiency and balance [5-8]. In all of these studies, dynamic effects of the robot are neglected such as inertia forces that may occur during the movement. Since the dynamic effects of the robot will be less in small robots, it is possible to ignore these effects and consider only the static balance in robot control.

Although these neglections do not pose a significant problem in insect type robots, where the robot weighs quite small, it would not be right to ignore these effects in a legged mobile robot big enough to meet the human needs. When the size of the leg robots is increased to meet human needs, problems such as the requirement of a robust robot design and development of a new dynamic computation techniques are encountered.

The first of these problems is the strength requirement of the robot. Although it is possible to overcome this problem with the use of durable materials, the same process will lead to an increase in weight, which will adversely affect the load-bearing capacity and energy efficiency of the robot. Eventhough this problem can be solved with new, lightweight and durable materials, it will significantly increases the cost.

The main reason why a control technique (which take all the dynamic effects into account) cannot be developed in legged mobile robots is the lackness of a calculation method to determine the reaction forces at the leg tips with all components. If the robot has more than three contacted legs on the ground, the inability to calculate the components of the contact forces is defined as the hyperstatic state. The contact force components that will occur if three legs touch the ground are shown in Figure 1 on an exemplary platform. 


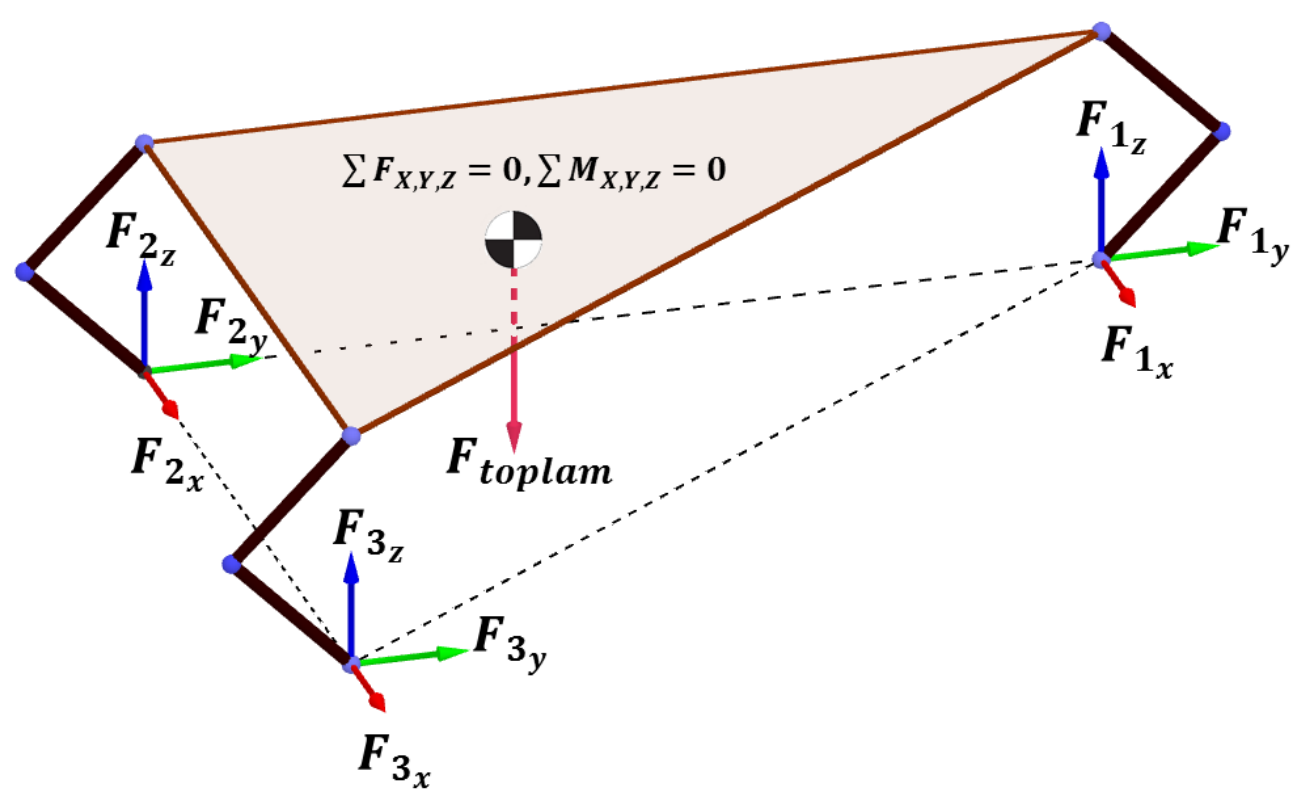

Figure 1. The contact force components in 3 leg contact situation

When calculating the contact forces on this platform, which has three legs in contact with the ground, it is technically possible to write six different equations. These are the force and moment static equilibrium conditions in all three direction (x,y and $\mathrm{z}$ ).Bu denklemler In these conditions, it is assumed that the sum of the linear forces in the $\mathrm{X}, \mathrm{Y}$ and $\mathrm{Z}$ axes and the moments around these axes are equal to zero. Since the number of forces tried to be determined in the system is nine, it is impossible to find a single solution using linear algebra techniques. There are infinitely different solutions in this equation set and nonlinear solution techniques are used to find the most accurate solution set.

In the legged mobile robot applications, there are examples that try to measure the force components at the contact points by placing the sensors at the leg's endpoints, instead of using a mathematical technique directly [9]. Since these sensors are very expensive and difficult to apply, they create serious problems in terms of cost.

If the contact forces at the leg tips are known, it becomes very easy to develop control techniques that take into account dynamic effects. The control technique refers, the application of forward dynamic analysis technique from the leg's contact point to the robot's main chassis, in order to obtain the external forces required for the joints. In the cases where contact forces are not known, the application of this dynamic analysis technique becomes impossible.

The dynamic calculations required for motion control of the legged robots are composed of highly complex operations [10]. Generally, legged robot control can be performed with a dynamic model which consisting of highly complex and nonlinear equations [11]. In the solution of these nonlinear characteristic equations, the solution can be done with the assumptions and constraints [12]. On the other hand with physics simulators such as Open Dynamics Engine (ODE), this modeling process can be performed in a simple way without the need for analytical solution of complex equations using iterative techniques [13].

Open Dynamics Engine (ODE), used for dynamic analysis of mechanical systems, was designed by Russell Smith in 2007 as an open source physics simulator [14]. Many developers have continued to contribute to the development of ODE until today. The latest version of ODE was published in June 2017 by Oleh Derevenko. The new versions have many advantages in terms of both speed and performance compared to the original version. In addition, with the new versions, it becomes possible to define the new types of joints and contact types according to users needs. Although the new releases provide performance improvements in ODE, the basic dynamic analysis algorithm has never changed.

It is possible to calculate the contact forces on a six-legged robot directly by using ODE, without the need for any special technique [15]. On the other hand, a model-based controller using ODE in its infrastructure can create a control plane in which the robot automatically balances itself quickly [16]. By operating this control plane continuously in an ODE based gait control algorithm, the robot can automatically compensate for external influences during walking [17].

In this study, firstly, an experimental system has been developed which consists of control ropes and a inclination platform, in order to reveal the performance of walking and stability controllers developed in previous studies. The performance of the ODE based gait and stability controllers was investigated on this developed experimental system. In order to determine the responses of the controllers to changing external conditions, the experiments were carried out seperately at a fixed flat angle and a case scenario in which the angles of the two axes were changed periodically. The previously developed stability and repeatability criterias were used for performance examinations [18]. In the performance analysis the same experiments were repeated for the standard gait patterns in order to reveal the contribution made to the literature. At the end of the study, the positive improvement achieved by ODE-based stability and gait controllers compared to standard gaits is revealed as a quantitative measure.

\section{ODE based stability and gait controllers}




\subsection{Layered control architecture}

In legged robots, a hierarchical control architecture is generally preferred at the control process [19]. In a hierarchical control architecture, the devices and control software used in the system are organized as a tree. Complex systems created by humans are often controlled in a hierarchy. In this control technique, problems are divided into smaller sub-problems and the problems are tried to be solved within a defined structure. For this reason, a hierarchical control structure will be used in the control operations performed within the scope of the study. At the bottom of this structure, which will be controlled by a total of 3 layers, there is an ODE dynamic model and an experimental robot. The layered control architecture used in the experimental system is given in Figure 2.

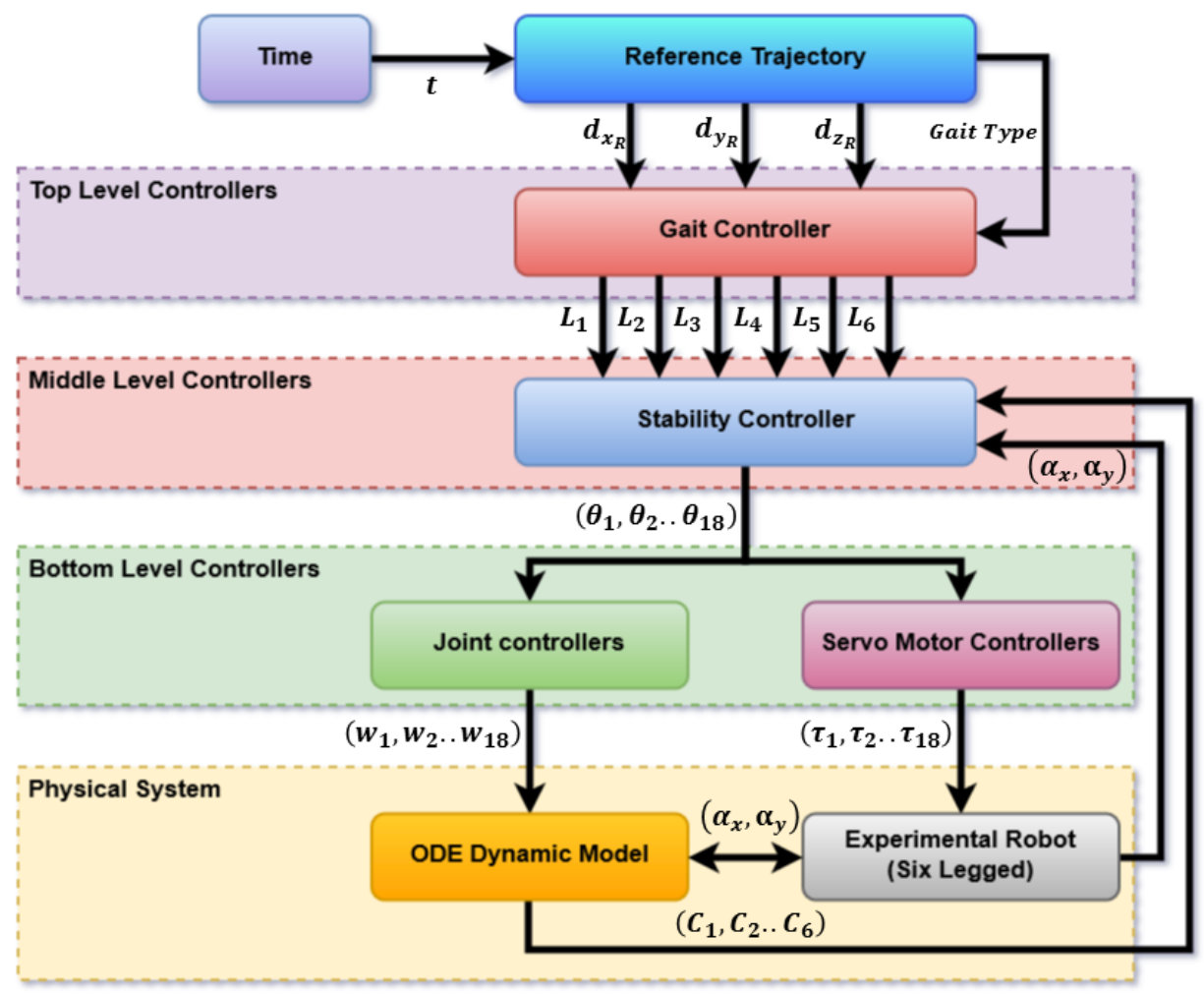

Figure 2. Block diagram of the layered control architecture for the experimental six-legged robot

\subsection{Servo motor an ODE based joint controllers}

Servo motors are robotic actuators which are used to apply the values such as position, speed, acceleration and torque to the joints between two different part. The servo motors used on the experimental robot have been selected in Dynamixel AX-12 type due to its flexible use and many features such as position, speed and torque control. In servo controllers, which basically have a feedback controller structure, the reference data received from the sensors on the system and the input values defined in the system are continuously compared and an error value is generatedThen, using internal controllers, control signals are generated according to this error value. These signals are then transmitted to the DC motors inside the servo motors to provide an output such as the desired position, speed and acceleration. Figure 3 shows the block diagram of the feedback controller on the Dynamixel AX-12 servo motors.

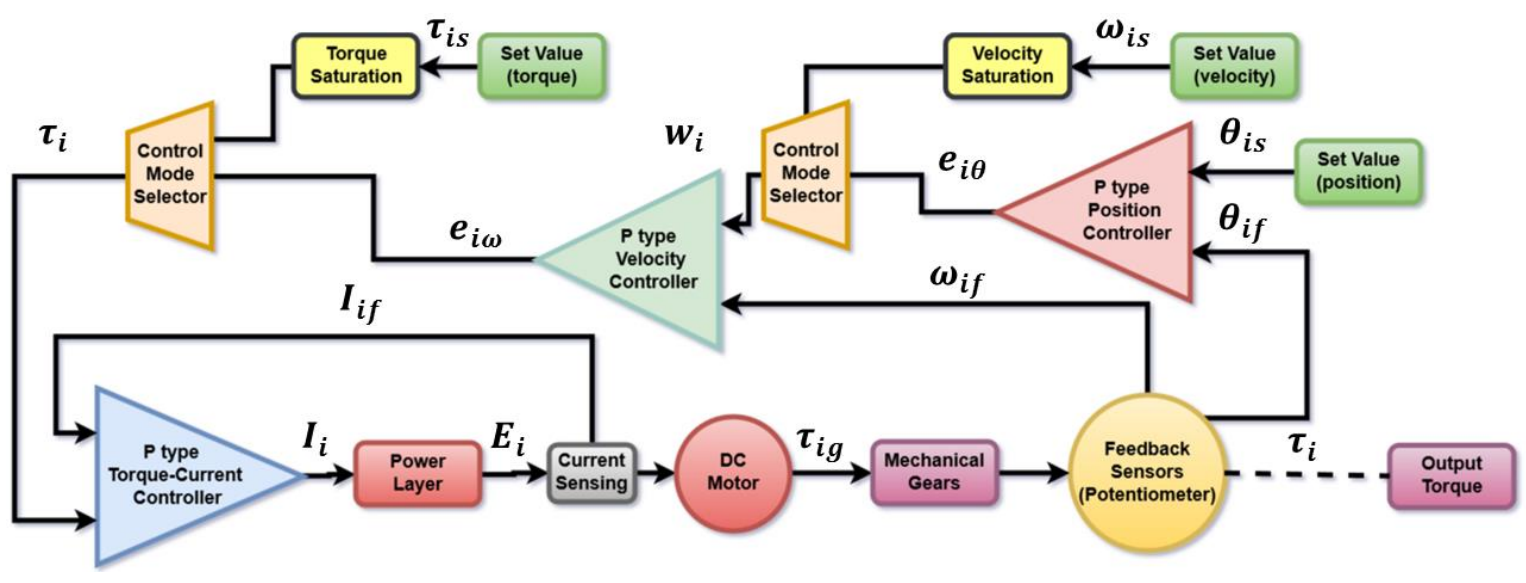

Figure 3. The block diagram of the controller on AX-12 servo motors 


\subsection{ODE based stability controller}

One of the main control objectives in legged mobile robots is to achieve balance during movement. Maintaining the balance throughout the movement will eliminate the possibility of the robot's tumbling. In addition, a more efficient movement will be realized since the load amount to the joints will decrease in the case of a balanced walk. The most stable posture of a legged robot is the case where the projection of the center of gravity on the ground and the center of the contact polygon intersects with. In order to intersect the center of gravity and the contact polygon center, the body, which is the heaviest part of the robot, needs to be moved in a direction that minimizes the error value defined in section 3. Figure 4 shows the ODE-based stability algorithm that performs this balancing process.

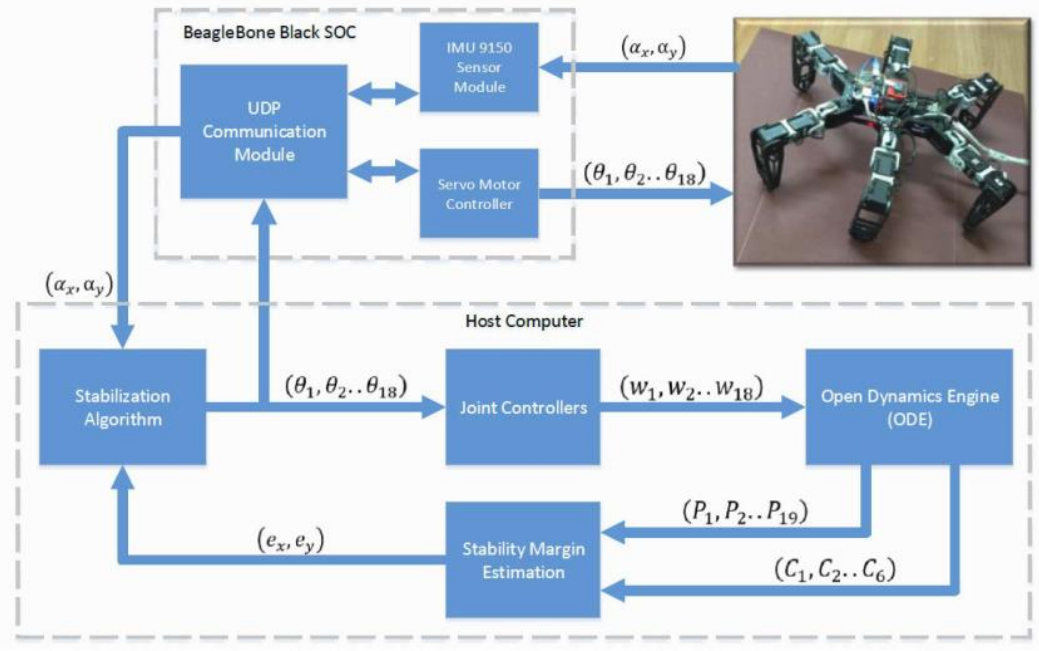

Figure 4. ODE-based stability algorithm [16]

In the ODE cycle, the above-mentioned operations are performed sequentially and the robot automatically balances itself according to the externally disturbing factors. In addition, the calculation of the compensation error in this developed controller is based on the contact polygon formed by the legs in contact with the ground, if one or more of the legs are cut off from the ground, the robot will try to stabilize itself according to this new situation.

\subsection{ODE based gait controllers}

Another difference between the walking creatures in nature is the diversity in the sequential orders, according to the movement type or speed. This sequence of leg movements, which can vary even in different movements (walking, running, galloping, etc.) seen on the same organism, is referred to as walking gait in the literature.

The purpose of the ODE physics simulator in the gait controller is to take into account the inertia forces that will result from acceleration during movement. Thanks to the previously developed ODE based joint and stability controllers, a control structure has been developed in which the robot can automatically stabilize itself according to both the effects from these inertial forces and the disturbing effects from the outside. The gait controller is located on the top layer of the three-layer control architecture given in Figure 2. The purpose of this controller is to move the legs of the robot in a suitable order according to the walking arrangement defined to it. Figure 5 shows the ODE-based gait controller.

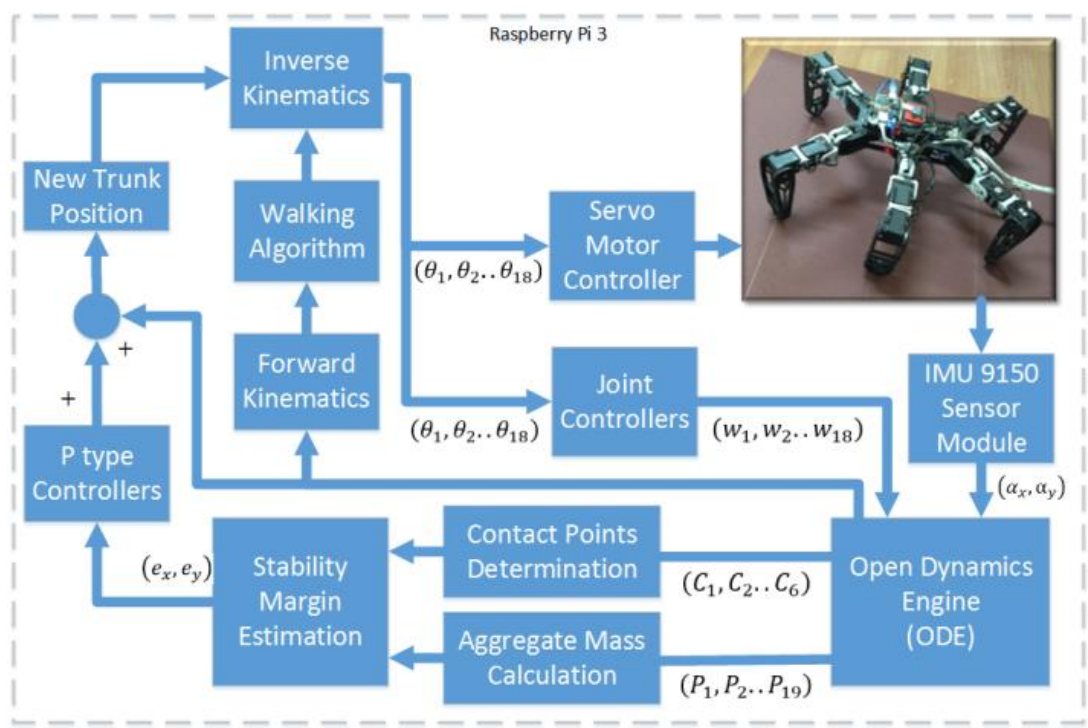

Figure 5. ODE based gait controller [17] 
In addition to this control architecture, there is a need to add a gait controller to the robot to move the robot from one location to another. Figure 6 shows two different contact polygons on the robot. The contact polygon is defined as a polygon whose corners are formed by the end points of the robot's ground-contacting legs. The $C_{\text {first }}$ polygon shown in the figure represents pre-movement, $C_{\text {last }}$ polygon represents contact polygons in the post-movement state. The $d_{x}$ and $d_{y}$ march distances are used to define the displacement quantities that the leg will perform after a one-foot step according to a fixed reference axis placed in the ground plane. The term $d_{z}$ is used to describe the elevation displacement of the transient position of the leg in the movement phase.

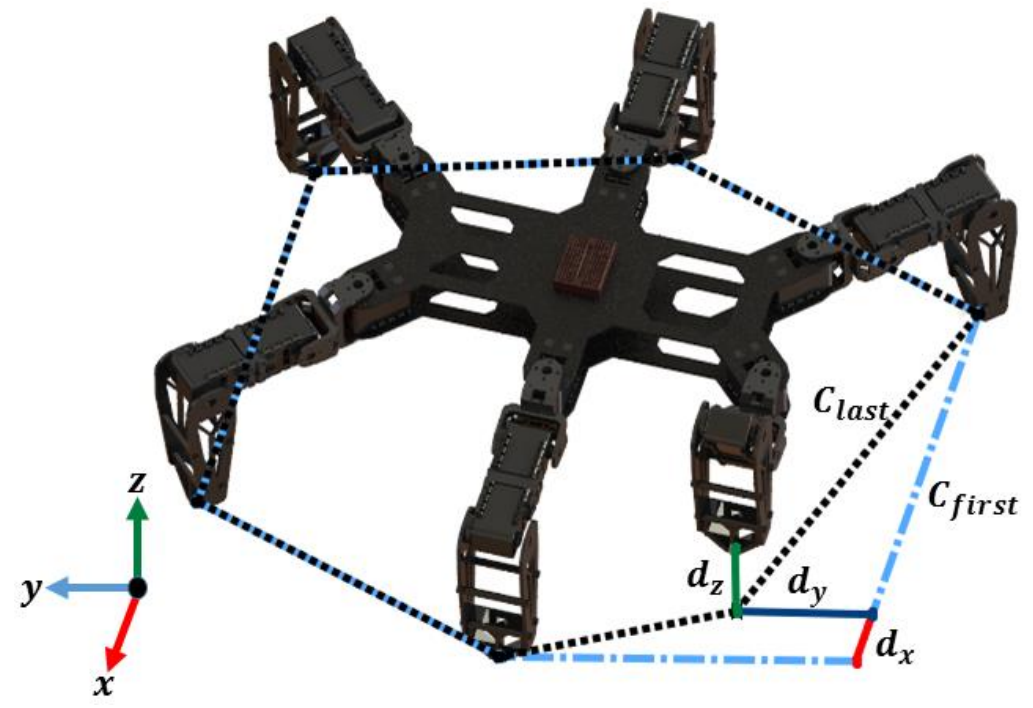

Figure 6. The contact polygons (pre-movement and post-movement state)

Each leg movement (foot-step) consists of two phases in total. In the first phase, the end point of the leg is moved forward by $d_{x}$ and $d_{y}$ to be transmitted to the point where it will find the next step. The end point of the leg is increased by the distance $d_{z}$ during the movement, so that the leg breaks from the ground correction during movement to perform a more comfortable movement. In the second phase of the leg movement, the end point of the leg is lowered to the ground only by the distance $d_{z}$ so that the distances $d_{x}$ and $d_{y}$ are maintained. This $d_{x}$ and $d_{y}$ and the displacements applied sequentially to all legs according to the gait pattern to allow the robot to complete a complete step. Figure 7 shows the flow diagrams of the gait control algorithms added to the ODE-based stability controller for three different gait type. For more detailed information about algorithms, study [20] can be examined.

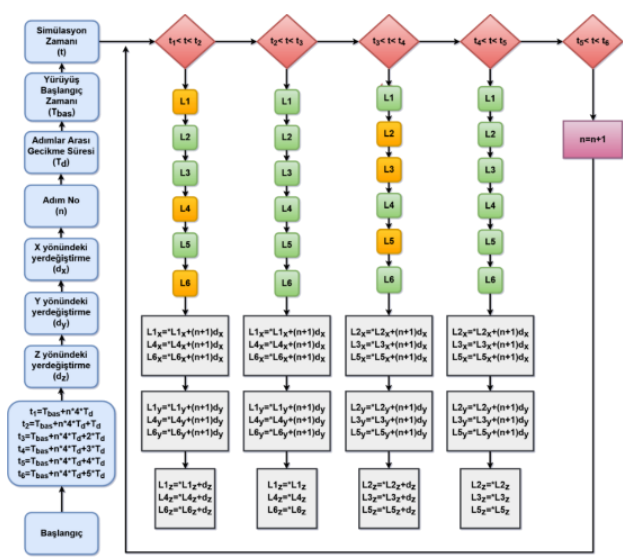

a)

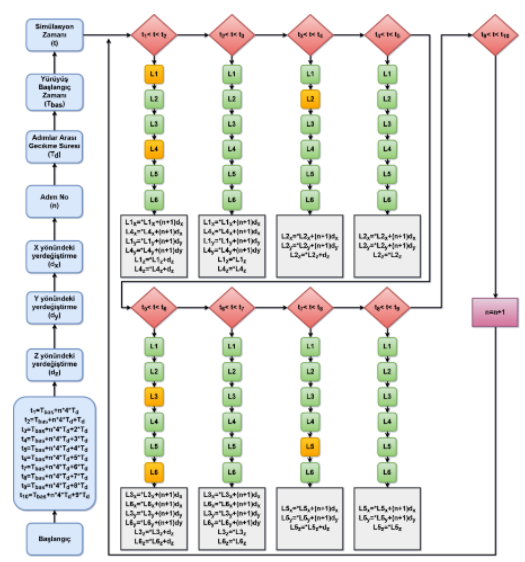

b)

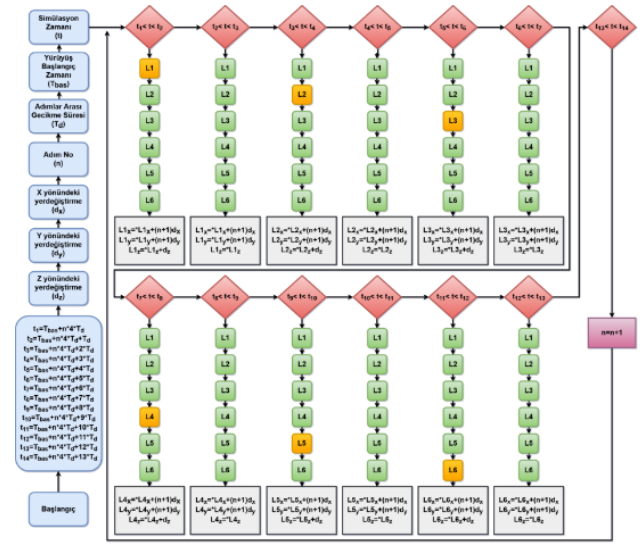

c)

Figure 7. The flow diagrams of gait control algorithms (a-tripod, b-ripple, c-wave)

\section{Standard walking gaits}

While designing a walking gait for six-legged mobile robots, scientific studies are generally carried out taking into account the movements of living organisms or insects. These movements refer to the leg movement sequences used by the living thing to reach another position. Even in the same creature, different walking patterns can be seen at different speeds. The definition of steps in the movements of leg organisms is not only used for the movement of a leg. The term step in walking creatures is defined as the movement of the living thing from its current position until it returns to the same posture after a specified amount of progress. The term footstep is generally used for the movements of each leg. Robots with a large number of legs, such as six-legged creatures, can be made in many different combinations of sequences. However, these gait sequences must be designed to maintain the stability of the robot. These step differences are known as gait in the legged robot literature. 
In six-legged robot applications, three different gait patterns are generally used to maintain balance during movement. These walking schemes are called Wave, ripple and tripod respectively. Figure 8 shows the leg numbers for an example six-legged mobile robot and the order in which these legs move in three different gait patterns.

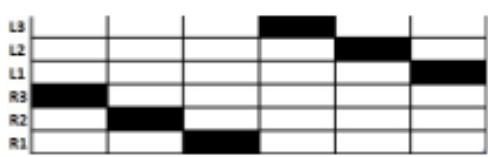

(a)

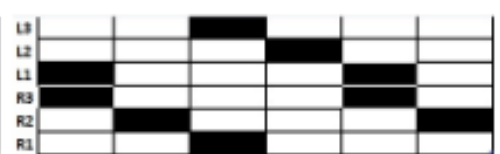

(b)

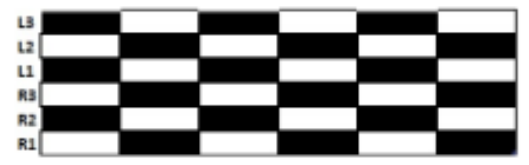

(c)

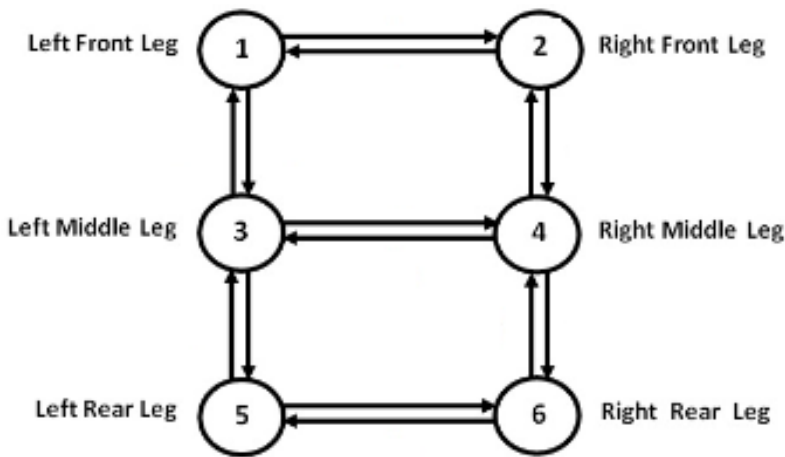

Figure 8. Standard walking gaits (a-tripod, b-ripple, c-wave) [21]

\section{Performance criterias}

\subsection{Static stability criteria}

In control systems, the term stability margin is used for the minimum degradation value that will make the system boundary stability. Boundary stability conditions in leg mobile robots are situations where the projection of the robot's center of gravity (CoG) on the ground plane and the edges of the contact polygon intersects with. Because out of this line, the robot will fall over into an unstable state, and inside it will continue to maintain its stability in a determined manner. For this reason, the stability in leg mobile robots depends mainly on the relationship between the contact polygon and the position of the robot's average center of gravity.

The main purpose of control systems is to successfully perform a predefined task on the controlled system. While measuring the performance of control systems, it is necessary to determine how much of this task is completed successfully. For this reason, a stability margin is needed both to use as a correction factor in the stabilization algorithm and to measure the performance of the gait controller to be compared within the scope of the study. In the literature, many different kinds of stability margins can be defined for evaluating static walking performance in leg mobile robots. The most important and most used of these margins is undoubtedly the stability criterion known as Static Stability Margin (SSM). This criterion is shown in Figure 9 on the contact polygon.

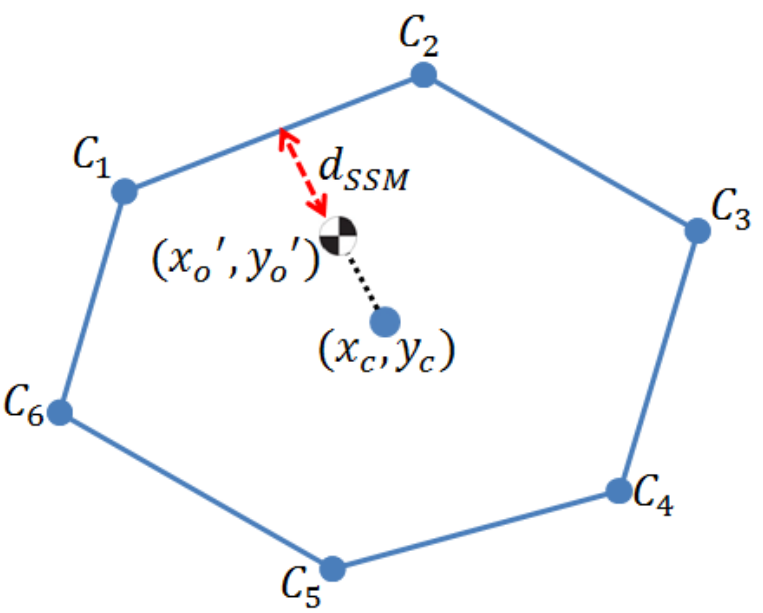

Figure 9. Static Stability Margin (SSM) on a Contact Polygon

In order to determine the static stability margin, firstly the position of the robot's average center of gravity in space is needs to be find. While determining the average center of gravity of the robot, the positions of all parts of the robot in space and the weighted averages of their mass values are taken. The expressions given between equation 1 and 3 are used to find the average center of gravity.

$$
\begin{gathered}
m_{T}=\sum_{i=1}^{n}\left(m_{i}\right) \\
x_{o}=\frac{1}{m_{T}} \sum_{i=1}^{n}\left(x_{i} \cdot m_{i}\right) \\
y_{o}=\frac{1}{m_{T}} \sum_{i=1}^{n}\left(y_{i} \cdot m_{i}\right)
\end{gathered}
$$

In the equations, the term $m_{i}$ is the mass value of the $\mathrm{i}$ th limb, the term $n$ is the number of limbs used in the robot, the term $m_{T}$ is the total mass of the robot, the term $x_{i}$ represents the position of the $\mathrm{i}$ th body on the $\mathrm{x}$ axis relative to the axis set defined on the body, 
the term $y_{i}$ represents the position of the $\mathrm{i}$ th body on the $\mathrm{y}$ axis relative to the axis set defined on the body, and the terms, $x_{o}$ and $y_{o}$ represent the positions of the average center of gravity of the robot relative to the axis set in the body. Once the robot's average center

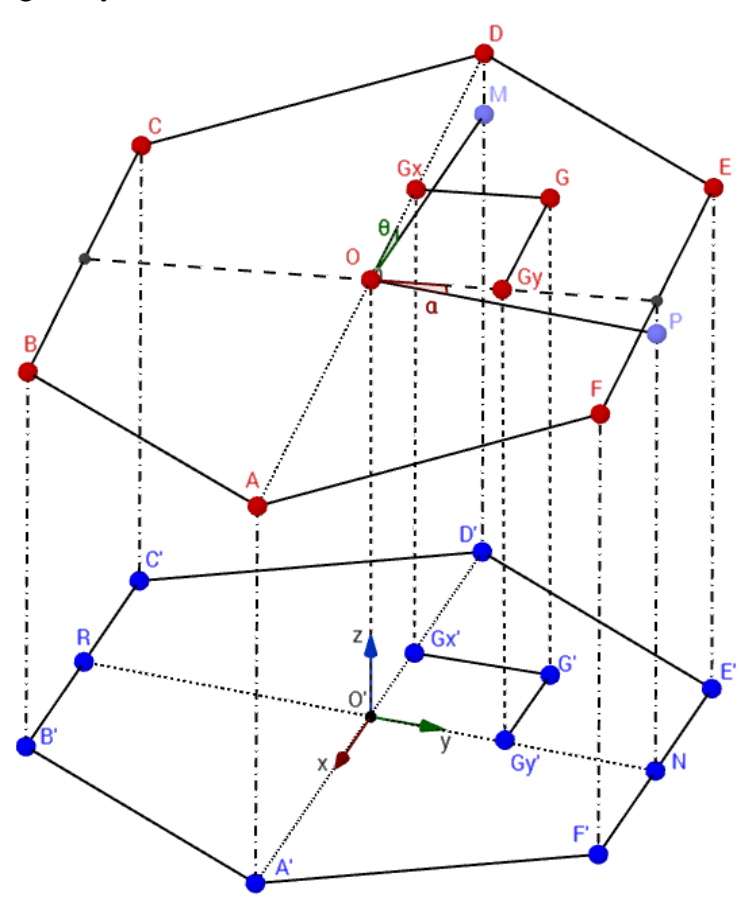
of gravity is found, it must be projected onto the ground plane (projection). This process is shown schematically in Figure 10 .

Figure 10. The projection of the center of gravity $(\mathrm{CoG})$ to the ground plane [16]

Equations 1-3 are used to calculate the position of the average center of gravity relative to a set of moving axes placed on the body of the robot. The IMU sensor, which is placed in the body of the robot, makes it possible to measure the angular position of the body relative to the fixed ground plane. The angular positions $\alpha_{x}$ and $\alpha_{y}$ around the $\mathrm{X}$ and $\mathrm{Y}$ axes relative to the global axis set are shown in the figure. If the height $h_{R}$ of the center of gravity placed on the body is kept constant during the movement of the robot, the projection $\left(x_{O}^{\prime}, y_{O}^{\prime}\right)$ of the average center of gravity on the ground plane is calculated by the expressions given in equations 4 and 5 .

$$
\begin{aligned}
& x_{O}{ }^{\prime}=x_{O}+h_{R} \cdot \tan \alpha_{x} \\
& y_{O}^{\prime}=y_{O}+h_{R} \cdot \tan \alpha_{y}
\end{aligned}
$$

In addition,the position of the center of the contact polygon shown in Figure 9 must be determined to calculate the static stability margin. The polygon center determination formulas given in 6-8 are used to find this position.

$$
\begin{gathered}
A=\frac{1}{2} \sum_{\mathrm{I}=1}^{n}\left(x_{i} \cdot y_{i+1}-x_{i+1} y_{i}\right) \\
x_{c}=\frac{1}{6 A} \sum_{\mathrm{I}=1}^{n}\left(x_{i}+x_{i+1}\right)\left(x_{i} \cdot y_{i+1}-x_{i+1} y_{i}\right) \\
y_{c}=\frac{1}{6 A} \sum_{\mathrm{I}=1}^{n}\left(y_{i}+y_{i+1}\right)\left(x_{i} \cdot y_{i+1}-x_{i+1} y_{i}\right)
\end{gathered}
$$

Normally, the static equalization margin (SSM) is defined by the shortest distance of the robot's average center of gravity to the edges of the contact polygon. The higher the value, the more stable the robot stands. A smaller value means a more unstable posture. In cases where the static equalization margin is negative, the posture is unbalanced, which means that a tumbling motion will start in the direction of the error. Within the geometric area covered by the contact polygon, the position farthest away from the edges is the position of the polygon center. This point is represented by the term $\left(x_{c}, y_{c}\right)$ in Figure 11 . 


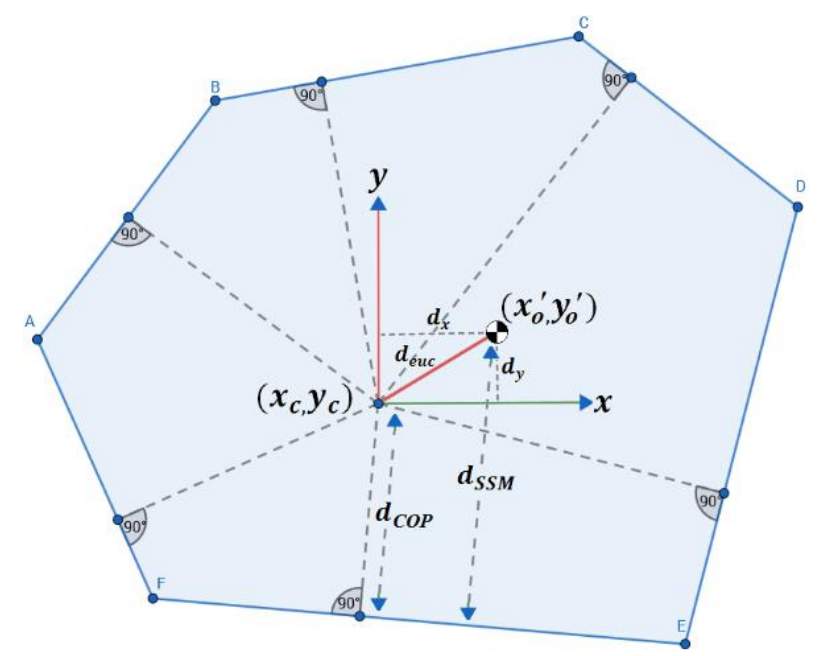

Figure 11. The error values defined on the contact polygon [16]

In the developed stability controller, two different error values must be defined since two different axes will be controlled. Compensation errors in the $\mathrm{X}$ and $\mathrm{Y}$ directions are defined by the expressions given in equations 9 and 10 below.

$$
\begin{aligned}
& e_{x}=x_{c}-x_{o}{ }^{\prime} \\
& e_{y}=y_{c}-y_{o}{ }^{\prime}
\end{aligned}
$$

The term $e_{x}$ and $e_{y}$ represents the difference distances on the $\mathrm{x}$ and $\mathrm{y}$ axis relative to the ideal position of the main frame. In addition to this error value, a performance criterion is needed to evaluate the overall movement in the gait control section. For this purpose, the Euclidean distance is used to represent the error between the center of gravity of the contact polygon and the center of gravity. The euclidean error between these two points is calculated by the equation given in equation 11. In order to establish a single performance criterion to represent the quality of the entire gait, the integral of this error term in formula 12 is taken over the entire gait time.

$$
\begin{gathered}
d_{\text {euc }}(t)=\sqrt{\left(e_{x}(t)\right)^{2}+\left(e_{y}(t)\right)^{2}} \\
e_{\text {alan }}=\int_{0}^{T} d_{e u c}(t) d_{t}
\end{gathered}
$$

\subsection{Resemblance criteria}

Most of the stability margins are used to represent the current stabilization level of the robot numerically. Therefore, these stability margins do not give us any information about the whole gait. On the other hand, the ODE-based gait controller may occasionally display irregular behavior if the parameters are set incorrectly. In Figure 12, the regular progressive change of the timedependent Euclidean error of a standard tripod gait and the irregular behavior obtained as a result of the ODE-based tripod gait are shown.
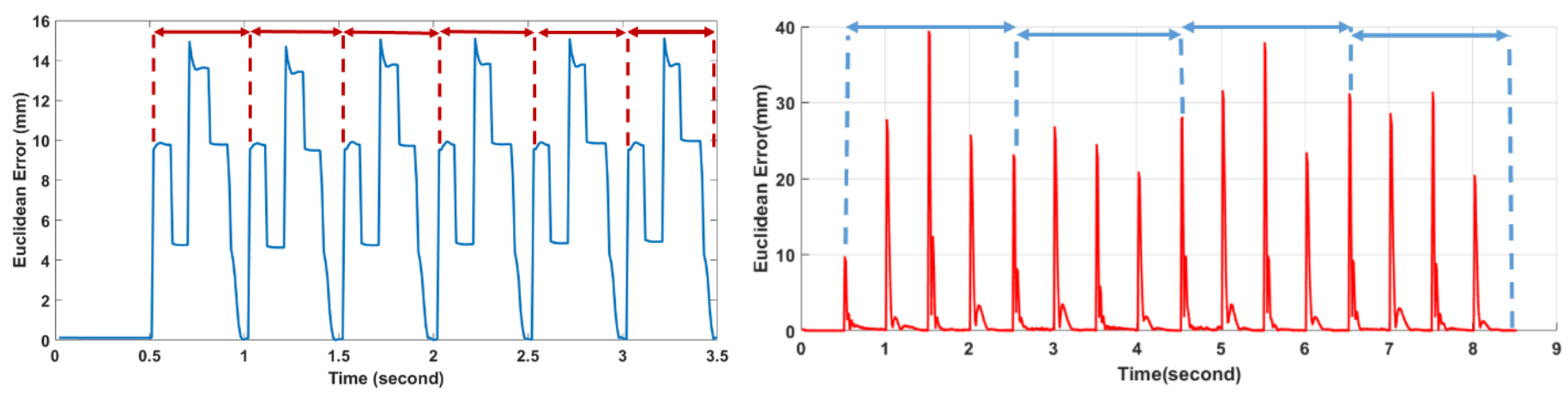

Figure 12. The regular behavior of standart tripod(left) and the irregular behavior of ODE based tripod (right) [16]

For this reason, there is a need for a new performance criterion that indicates whether the movement is periodic or not. A new performance criterion based on standard deviation formula has been developed to express the similarities of steps during gait. The equation used to obtain this performance criterion proposed in Equation 13 is as follows.

$$
e_{s}=\frac{1}{N}\left(\sum_{i=1}^{M}\left(\sum_{j=1}^{N}\left(s_{j}(i)-\frac{1}{N} \sum_{k=1}^{N} s_{k}(i)\right)^{2}\right)\right)
$$




\section{Experimental System}

\subsection{Experimental Robot}

A six-legged mobile robot was used in the experiments in this applied research study. The robot used experimentally has a total of eighteen degrees of freedom, three degrees of freedom on each leg. Total weight of the robot including servo motors, battery and electronic equipment is $2.4 \mathrm{~kg}$. The designed version of the robot used in the experiments is given in Figure 13. As can be seen in the figure, each leg consists of three limbs in order of connection to the body. These limbs are called coxa, tibia and femur respectively from the trunk to the tip. Each leg used in the robot is designed to be identical. These legs are placed on the body at different angles and positions. There are eighteen servo motors on the robot, one for each joint. These servo motors are of the Dynamixel AX-12 type. In these servo motors, which are preferred because of their light and high power, the speed and position control of the motor can be made as well as the torque control by changing the upper limit of torque. The height of the robot at the standard stand position is 16.2 $\mathrm{cm}$. A three-cell Li-Po battery is used on the robot to meet the power requirements of the motors and electronic equipment on the robot. This battery has an energy storage capacity of $2200 \mathrm{mAh}$. When the battery is fully charged, the robot can move continuously for 25 minutes.
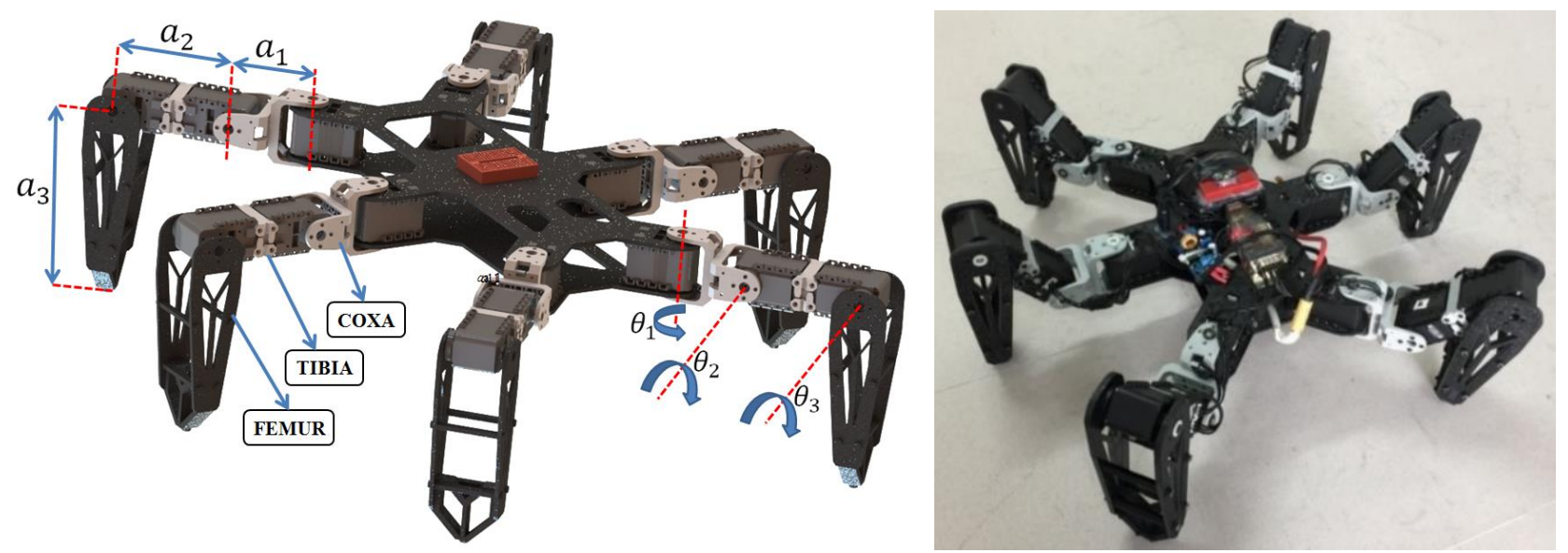

Figure 13. The design of six-legged robot used in experiments and the experimental robot [16]

The projection of the robot's center of gravity is located at the center of the main chassis. The maximum amount of displacement that the robot can travel along the $\mathrm{x}$-axis without tumbling in tripod gait's single cycle is $9 \mathrm{~cm}$. The six-legged robot used in the experiments is given in Figure 13. The body of the robot consists of two different plastic materials. The first of these are the frame fittings of the servo motors. These parts are white parts that appear on the robot shown in Figure 13. All the other parts used in the robot has manufactured by laser cutting from a high hardness ABS plastic plate.

\subsection{Inclined Floor}

In order to demonstrate better the performance improvement shown by the ODE-based gait controller, a movable platform has been constructed which can be angularly moved about two axes. The size of this platform determined as $2 \times 1$ meters. Rope and roller control mechanisms operating according to the principle of counter balancing load have been established both because the ground to be controlled by changing its angle is too large and the platform angle given during walking is not affected by robot movement. In these mechanisms, the ropes are passed through movable linear slides placed on the wall. In this way, both the angle at which the platform is located can be controlled with two different ropes and the angles at which the platform is located can be measured via a display plate fixed to the wall. This inclination platform can be seen in figure 14. 


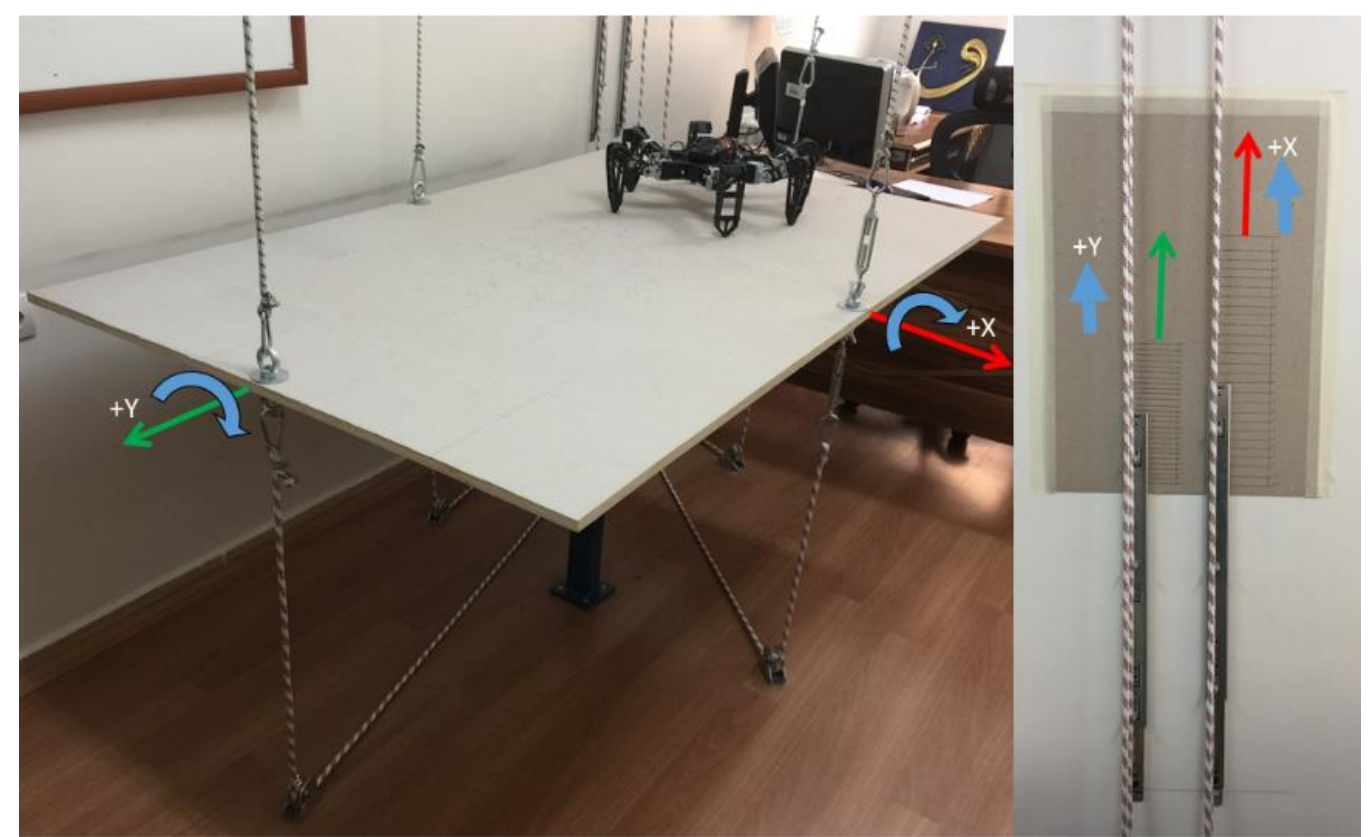

Figure 14. The experimental inclination platform

\subsection{Inclination Scenerio}

Experiments to compare gait patterns consisted of 5 steps in total. In each gait, the completion time is different. In ODE-based tripod gait, one step is completed in 2 seconds, in ODE-based ripple gait this is 4 seconds and in ODE-based wave gait takes 6 seconds. The time taken for one step in a standard tripod gait is completed in 2.5 seconds, while the standard ripple gait is 4.5 seconds and the standard wave gait is 6.5 seconds. The reason that the times in ODE-based gait patterns differ from the times in standard gait patterns is that the step movement in ODE-based gait control can be completed in one phase shorter due to the automatic balancing process. Although the ODE-based gait controller can be adjusted with the delay times between the steps, the delay time between the steps is kept constant in all experiments at $0.5 \mathrm{~s}$ in order to compare the gait patterns accurately with each other. A periodic test scenario has been developed to be applied to the moving platform in order to test the gait patterns with different periods of time under the same disturbing factors.

This periodic test scenario takes 10 seconds in total. The angle of the $\mathrm{X}$ and $\mathrm{Y}$ ropes that control the platform changed to different values in every 2 seconds during the scenario. In other words, the control ropes will be intervened 5 times in this scenario process, which will be carried out periodically during the experiments. Platform angles $\left(\mathrm{x}=0{ }^{\circ}, \mathrm{y}=0^{\circ}\right)$ are kept at the beginning of the scenario. With the first disturbance to be made in the 2 second of the scenario, platform angles are brought to $\left(\mathrm{x}=0{ }^{\circ}, \mathrm{y}=10^{\circ}\right)$. Then sequentially the platform angles are brought to $\left(\mathrm{x}=0^{\circ}, \mathrm{y}=-10^{\circ}\right)$ with disturbance at 4 seconds, are brought to $\left(\mathrm{x}=-11^{\circ}, \mathrm{y}=-10^{\circ}\right)$ with disturbance at 6 seconds, are brought to $\left(\mathrm{x}=11^{\circ}, \mathrm{y}=-10^{\circ}\right)$ with the disturbance and finally the platform angles are brought to $(\mathrm{x}$ $=0^{\circ}, \mathrm{y}=0^{\circ}$ ) with the disturbance made at the 10th second of the scenario. This scenario, which is used to change the angles of the moving platform at certain times, will be used in all walking patterns to be tested in the experiments. If the tests of the walking gaits take longer than 10 seconds, the scenario will be restarted in every 10 seconds and will continue to be reinitiates again. Figure 15 shows the time-dependent periodic changes of this scenario to be used in the experiments.

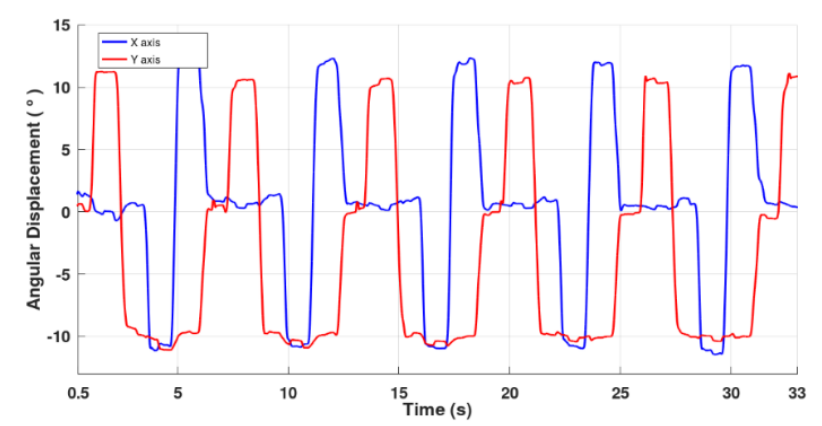

Figure 15. The periodic change of inclination scenario used in experiments

\section{Comparison Results}

In this section, some test results will be given in order to show the performance improvement of ODE based gait controller. The experiments will be carried out under two main headings. In both titles, the results of tripod, ripple and wave gait patterns will be given for both standard gait and ODE based gait patterns respectively. In the first part, the robot will be carried out on a flat surface. In the second part, the angles of the moving platform on which the robot is located will be changed during the gait. Thus, the performance improvement of the gait controller on both flat ground and a moving plane will be examined. 


\subsection{Experiment's on Flat Floor}

\subsubsection{Standard Tripod vs ODE based Tripod}
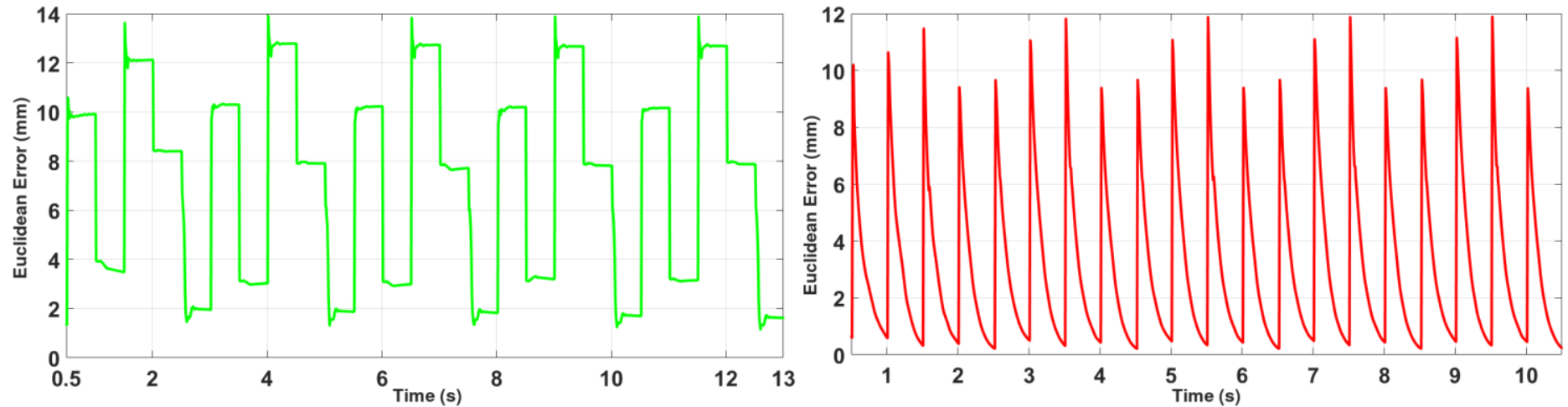

Figure 16. The comparison of Standard tripod(left) and ODE based tripod(right) on a flat floor

\subsubsection{Standard Ripple vs ODE based Ripple}
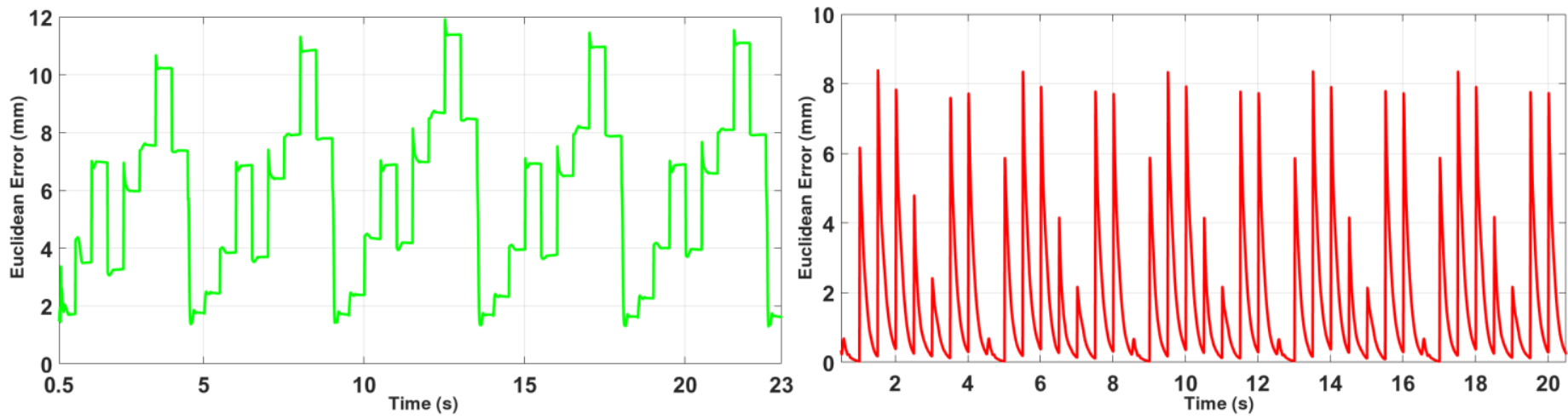

Figure 17 The comparison of Standard ripple(left) and ODE based ripple (right) on a flat floor

\subsubsection{Standard Wave vs ODE based Wave}
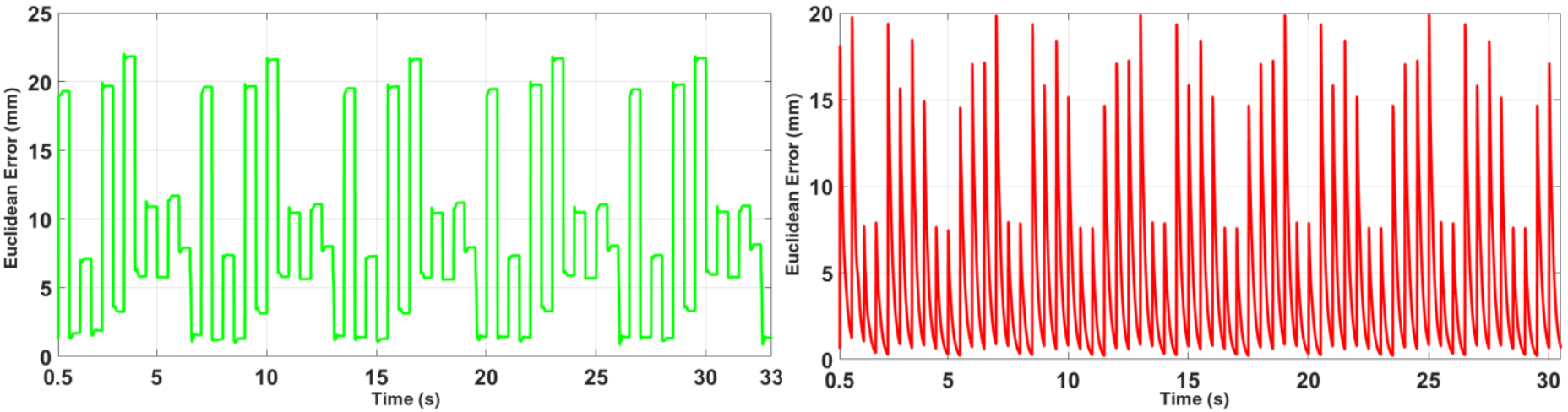

Figure 18. The comparison of Standard wave (left) and ODE based wave (right) on a flat floor

\subsubsection{Comparison table}

Table 1. The performance results of walking gaits tested on flat platform

\begin{tabular}{c|c|c|c|c}
\hline Gait type & $\begin{array}{c}\text { Area Error } \\
(\mathbf{m m . s})\end{array}$ & $\begin{array}{c}\text { Deviation } \\
\text { Error }\end{array}$ & $\begin{array}{c}\text { Movement } \\
\text { speed } \\
(\mathbf{m m} / \mathbf{s})\end{array}$ & $\begin{array}{c}\text { Improvement } \\
(\mathbf{\%})\end{array}$ \\
\hline Standard Tripod & 90,127 & 20,082 & 8 & \multirow{2}{*}{66,048} \\
\hline ODE based Tripod & 30,600 & 15,976 & 10 & \multirow{2}{*}{74,930} \\
\hline Standard Ripple & 131,4181 & 36,291 & 4,44 & 5 \\
\hline ODE based Ripple & 32,946 & 2,533 & 5 & 5,645 \\
\hline Standard Wave & 292,446 & 60,761 & 3,08 & 65,541 \\
\hline ODE based Wave & 129,714 & 54,704 & 3,33 & \\
\hline
\end{tabular}




\subsection{Experiments on a periodically inclined platform}

\subsubsection{Standard Tripod vs ODE based Tripod}
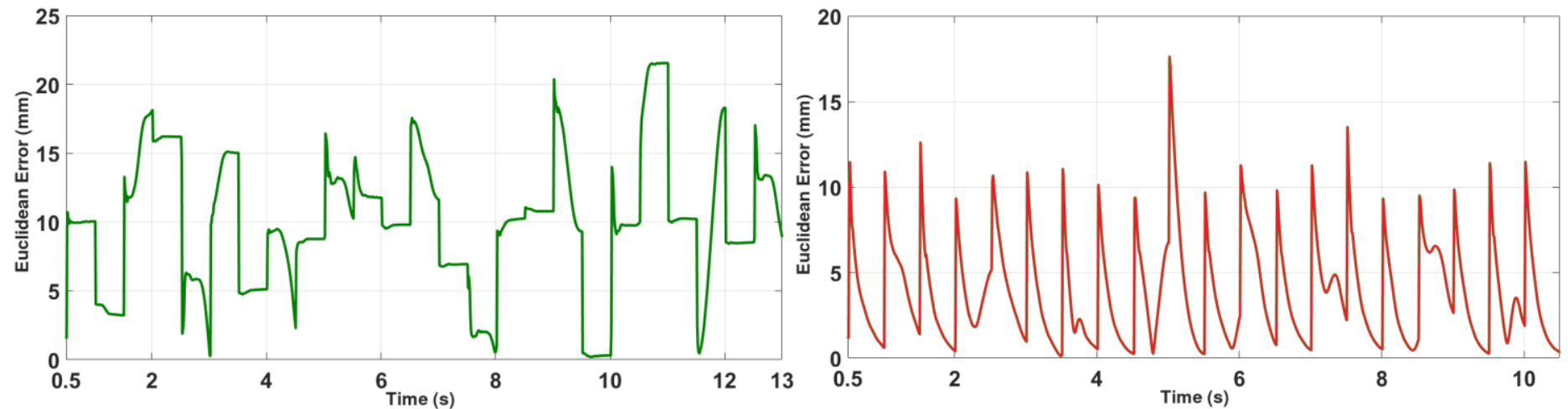

Figure 19. The comparison of Standard tripod(left) and ODE based tripod(right) on inclined floor

\subsubsection{Standard Ripple vs ODE based Ripple}
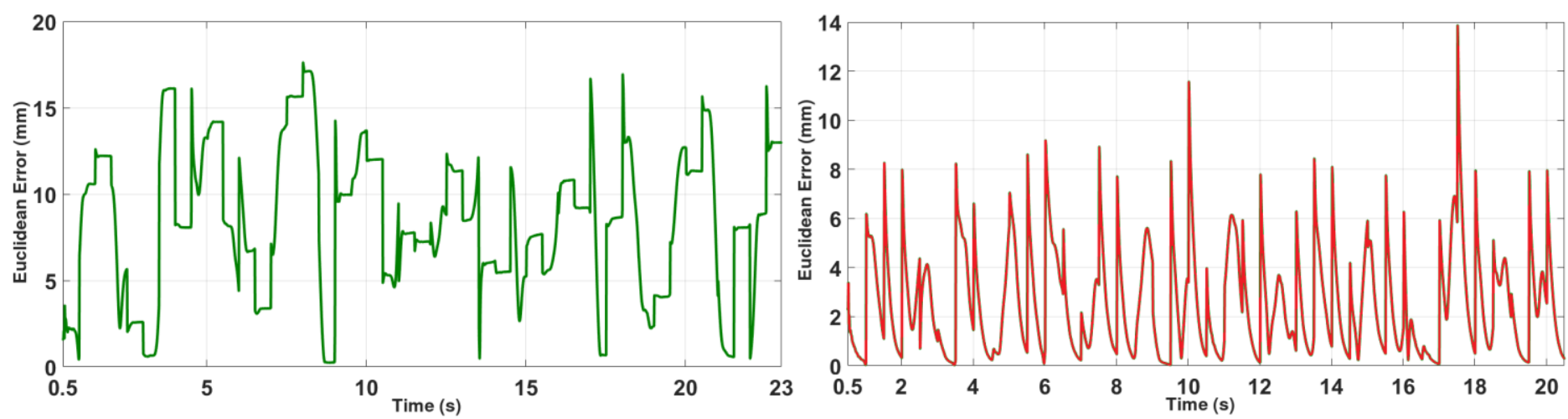

Figure 20. The comparison of Standard ripple (left) and ODE based ripple (right) on inclined floor

\subsubsection{Standard Wave vs ODE based Wave}
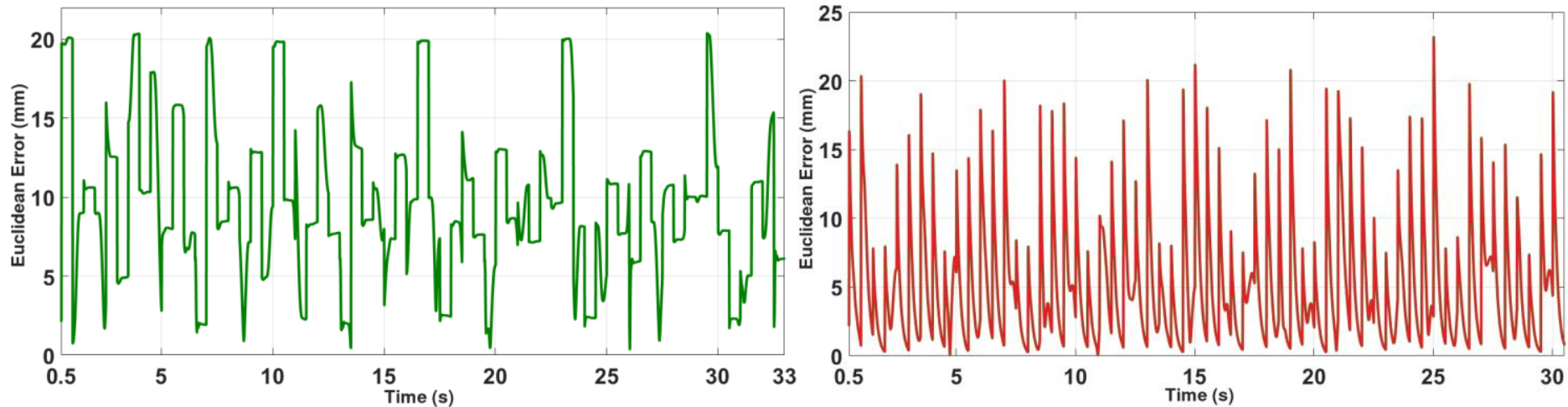

Figure 21. The comparison of Standard wave(left) and ODE based wave (right) on inclined floor

\subsubsection{Comparison table}

Table 2. The performance results of walking gaits tested on inclined platform.

\begin{tabular}{c|c|c|c|c}
\hline Gait type & $\begin{array}{c}\text { Area Error } \\
(\mathbf{m m} . \mathbf{s})\end{array}$ & $\begin{array}{c}\text { Deviation } \\
\text { Error }\end{array}$ & $\begin{array}{c}\text { Movement } \\
\text { speed } \\
(\mathbf{m m} / \mathbf{s})\end{array}$ & $\begin{array}{c}\text { Improvement } \\
(\mathbf{\%})\end{array}$ \\
\hline Standard Tripod & 124,614 & 4651,078 & 8 & \multirow{2}{*}{69,06} \\
\hline ODE based Tripod & 38,556 & 389,703 & 10 & \multirow{2}{*}{72,24} \\
\hline Standard Ripple & 188,806 & 6931,243 & 4,44 & 5 \\
\hline ODE based Ripple & 52,414 & 833,720 & 51,11 \\
\hline Standard Wave & 307,755 & 3744,512 & 3,08 & 6 \\
\hline ODE based Wave & 150,454 & 1212,521 & 3,33 & 64,14 \\
\hline
\end{tabular}




\section{Results and Discussion}

With the ODE-based gait controller, the walking of six legged robot becomes both faster and more stable. Although it varies according to the selected walking gait, the new gait patterns produced with the ODE-based gait controller improved the euclidean error $65 \%$ averagely compared to standard gait patterns. In order to demonstrate the performance improvement of the ODE-based gait controller compared to standard gait patterns, the experimental robot was carried out both on a flat platform and on a mobile platform whose inclination was changed over time. The ODE-based stability and gait controller resulted in a $65,541 \%$ improvement in walking on flat ground and a $64.14 \%$ improvement in walking on an experimental platform with a periodically modified slope. These improvement values obtained according to standard gait patterns are based on field error.

The reason why this improvement is so good is that the time used for the robot's self-balancing process between the steps is set to a value of 500 milliseconds. Because if the time between the steps is so large, the time-dependent numerical integral values of the Euclidean errors in standard gaits are quite large. In other words, the performance of the ODE-based gait control varies depending on the speed of the robot. For this reason, the increase in performance is only valid for this delay value. Although the increase in performance depends on robot speed, it is clear that even at very high speeds, the ODE-based gait controller will provide much better results than the standard gait patterns on the basis of stability errors.

\section{References}

1- Murray, R. M., Li, Z., Sastry, S. S., \& Sastry, S. S. (1994). A mathematical introduction to robotic manipulation: CRC press.

2- Vukobratović, M. (1975). Legged locomotion robots and anthropomorphic mechanisms: Mihailo Pupin Institute.

3- Siegwart, R., Nourbakhsh, I. R., \& Scaramuzza, D. (2011). Introduction to autonomous mobile robots: MIT press.

4- Ritzmann, R. E., Quinn, R. D., \& Fischer, M. S. (2004). Convergent evolution and locomotion through complex terrain by insects, vertebrates and robots. Arthropod Structure \& Development, 33(3), 361-379.

5- Inagaki, S., Yuasa, H., Suzuki, T., \& Arai, T. (2006). Wave CPG model for autonomous decentralized multi-legged robot: Gait generation and walking speed control. Robotics and Autonomous Systems, 54(2), 118-126.

6- Erden, M. S., \& Leblebicioğlu, K. (2008). Free gait generation with reinforcement learning for a six-legged robot. Robotics and Autonomous Systems, 56(3), 199-212.

7- Wang, Z., Ding, X., Rovetta, A., \& Giusti, A. (2011). Mobility analysis of the typical gait of a radial symmetrical six-legged robot. Mechatronics, 21(7), 1133-1146.

8- Kajita, S., Yamaura, T., \& Kobayashi, A. (1992). Dynamic gait control of a biped robot along a potential energy conserving orbit. IEEE Transactions on robotics and automation, 8(4), 431-438.

9- Nishiwaki, K., Murakami, Y., Kagami, S., Kuniyoshi, Y., Inaba, M., \& Inoue, H. (2002, May). A six-axis force sensor with parallel support mechanism to measure the ground reaction force of humanoid robot. In Proceedings 2002 IEEE International Conference on Robotics and Automation (Cat. No. 02CH37292) (Vol. 3, pp. 2277-2282). IEEE.

10- Nonami, K., Barai, R. K., Irawan, A., \& Daud, M. R. (2014). Historical and Modern perspective of walking robots Hydraulically Actuated Hexapod Robots (pp. 19-40): Springer.

11- Vukobratović, M., \& Stepanenko, J. (1973). Mathematical models of general anthropomorphic systems. Mathematical biosciences, 17(3-4), 191-242.

12- Vukobratović, M., \& Stepanenko, J. (1972). On the stability of anthropomorphic systems. Mathematical biosciences, 15(1-2), 137.

13- Koenig, N., \& Howard, A. (2004). Design and use paradigms for gazebo, an open-source multi-robot simulator. Paper presented at the Intelligent Robots and Systems, 2004.(IROS 2004). Proceedings. 2004 IEEE/RSJ International Conference on.

14- Eaton, M. (2007). Evolutionary humanoid robotics: past, present and future 50 years of artificial intelligence (pp. 42-52): Springer.

15- Estimation Of Contact Forces On Real-Time Six Legged Mobile Robot With ODE (Open Dynamİcs Engıne), YILDIRIM Ş., ARSLAN E., International Conference on Advances in Mechanical Engineering ICAME 2016, İstanbul, Türkiye, 10 - 13 May 2016, ss.185-190

16- ODE (Open Dynamics Engine) based stability control algorithm for six legged robot, YILDIRIM Ş., ARSLAN E. MEASUREMENT, cilt.124, ss.367-377, 2018

17- ODE (Open Dynamics Engine) Based Gait control Algorithm for Six Legged Robot, YILDIRIM Ş., ARSLAN E., JOURNAL OF NEW RESULTS IN SCIENCE (JNRS), cilt.7, ss.35-46, 2018

18- A New Walking Performance Criteria for ODE (Open Dynamics Engine) Based Six Legged Robot Control YILDIRIM Ş., ARSLAN E. The International Conference on Material Science, Mechanical and Automotive Engineerings and Technology, İzmir, Türkiye, 10 - 12 April 2018, ss.1-5

19- Campos, R., Matos, V., \& Santos, C. (2010, November). Hexapod locomotion: A nonlinear dynamical systems approach. In IECON 2010-36th Annual Conference on IEEE Industrial Electronics Society (pp. 1546-1551). IEEE.

20- Arslan, E. (2018). Parallel programming supported balance and walk control for six legged mobile robot (Phd. Thesis)

21- Belter, D., \& Skrzypczyński, P. (2012). Posture optimization strategy for a statically stable robot traversing rough terrain. Paper presented at the Intelligent Robots and Systems (IROS), 2012 IEEE/RSJ International Conference on. 